\title{
Structural Breaks and the Convergence of Regional House Prices
}

\author{
Mei-Se Chien
}

Published online: 24 July 2008

(C) Springer Science + Business Media, LLC 2008

\begin{abstract}
This paper differs from past research by examining the issue of whether regime changes have broken down the stability of the ripple effect. The endogenous two-break LM unit test, derived in Lee and Strazicich (Review of Economics and Statistics 85: 1082-1089, 2003), is used to execute the ripple effect tests. Being different from the empirical results of the conventional unit root tests without structural breaks, the empirical results of the endogenous two-break LM unit root test support the existence of ripple effects for each city in Taiwan except Taipei City. Shocks to regional house prices of Taipei City cannot "ripple out" across the nation, because Taipei City is a regional global city which has resulted in higher house prices, but does not affect the house prices of the entire area. Furthermore, the empirical evidence demonstrates the breakpoints and presents real estate policies, financial crises, and natural disease that can cause structural breaks of regional house prices.
\end{abstract}

Keywords Regional house prices $\cdot$ Ripple effect $\cdot$ Structural break

JEL Classification $\mathrm{R} 11 \cdot \mathrm{R} 21$

\section{Introduction}

Some prior works have focused on housing dynamics through different theoretical approaches, including neighborhood change, filtering, search, equity effects, urban growth, and housing chains. Empirical investigations of these models are uncommon due to the complexity of the models or a lack of data. Recently, an important line of empirical research referring to housing market dynamics has tested ripple effects for

M.-S. Chien $(\bowtie)$

Department of Finance, National Kaohsiung University of Applied Sciences, 415 Chien Kung Road,

Kaohsiung, Taiwan, 807

e-mail: cms@cc.kuas.edu.tw 
different regional house prices, implying the phenomenon that shocks to regional house prices "ripple out" across the economy and are caused by four factors: migration, equity transfer, spatial arbitrage, and spatial patterns in the determinants of house prices (Meen 1999).

Using Engle and Granger (1987) or Johansen (1988) cointegration tests, some studies investigate the notion of a causal link existing between different regional prices for houses, but the conclusions drawn from these relative studies are diverse. Applying standard house price models to regional data, MacDonald and Taylor (1993) and Alexander and Barrow (1994) suggest a ripple effect is present for finding the cointegration between regional house prices. Their results are consistent with related "ripple effects" studies, whereby if the forcing variables themselves display "ripples", then cointegration between regional house prices will exist. Contrary to this, Ashworth and Parker (1997) cast doubt on the ripple hypothesis using the ECM model and the Lagrange multiplier test.

As Meen (1999) indicates, the ripple effect implies a long-run constancy, or stationarity, in the ratio of house prices in different regions to the national figure. If a ripple effect indeed exists, then the ratio between each regional price and the national house price is stationary (see Meen 1999; Holmes and Grimes 2005; Cook 2005). Utilizing the ADF (of Dickey and Fuller 1979) unit root test, Meen (1999) finds evidence supporting stationarity in the regional-national house price ratios for the UK. Berg (2002) collects Swedish data, and for the period from January 1981 to July 1997 the Granger causality test shows that the Stockholm region leads price changes in the housing market- an effect that corresponds with the ripple effect in the UK.

Some research studies apply advanced econometric methodology to examine the ripple effect of regional house prices. Holmes and Grimes (2005) implement a new test that combines principal components analysis with unit root tests advocated by Elliot et al. (1996) and $\mathrm{Ng}$ and Perron (2001), and it has higher power and less size distortion relative to the ADF test. The empirical conclusion supports existing regional house price convergence in the UK based on finding long-run equilibrium relationships. They indicate that the house price shocks stemming from any region eventually "ripple out" to have the same effect on all regional house prices.

To test the stationarity of regional house price ratios, Cook (2005) employs an alternative method which includes the joint application of two tests, rather than following the approach of Meen (1999) who applies the ADF unit root test. The two tests are the DF-GLS test of Elliot et al. (1996) and the KPSS test of Kwiatkowski et al. (1992). This joint application of two tests has been employed as confirmatory analysis, for it makes the non-rejection by one test be 'confirmed' by rejection after using the other test. The results of Cook (2005) find supportive evidence of stationarity in regional house price ratios, which shows that the ripple effect is present in the UK.

Recent research studies find an asymmetric adjustment of many economic variables, which lower the power of the DF test (see Pippenger and Goering 1993). To improve the empirical results of Meen (1999), Cook (2003) re-examines the stationarity of regional house price ratios using the MTAR test of Newbold et al. (2001), allowing for the possibility of asymmetric adjustment about a stationary attractor. The application of this alternative approach supports that stationarity exists in a number of regions of the UK. Cook (2003) indicates that the failure of Meen 
(1999) to uncover convergence is due to underlying asymmetry in the adjustment process being ignored.

Few research studies investigate the spillover of housing price changes within neighboring areas. Clapp et al. (1995) find evidence of a spatial diffusion of housing price changes between neighboring towns, which covers towns in Connecticut and near San Francisco, but there are no changes across non-neighboring towns. The empirical results of Dolde and Tirtiroglu (1997) also support the same results by GARCH-M methods. Others investigate the ripple effect of housing submarket within a city. According to a synthesis of different models of housing market dynamics, Ho et al. (2007) examine spatial "ripple effects" across different quality tiers of housing within city of Hong Kong for the period 1987 to 2004. By the Granger causality test, the empirical results show that housing price and transaction volume changes, which are caused by housing policy changes, spread from low quality units to high quality ones throughout the quality continuum. Sing et al. (2006) empirically look at house price dynamics combined with the mobility of households in the public resale and private housing markets within Singapore. In the stochastic permanent breaks tests (of Engle and Smith 1999), the result shows that household mobility creates co-movements of prices in public and private housing submarkets in the long run. In the VECM estimations, price information will only spillover from one market to another on the housing ladder, if it is not segmented.

Most of the papers listed above unfortunately did not test structural breaks for exogenous shocks or regime changes. It is important to check structural breaks if the empirical periods cover an unstable time of social and economic development. The conventional unit root tests may be queried, not considering that the structural breaks could cause an incorrect inference. Perron (1989) proposes allowing for one known, or "exogenous," structural break in the ADF unit root test. Following Perron (1989), Zivot and Andrews (1992) and Perron (1997) offer to determine the break point "endogenously" from the data. A potential problem common to the ADF-type endogenous break unit root tests is that they derive their critical values assuming no break(s) under the null. This assumption leads to size distortions in the presence of a unit root with a break as Nunes et al. (1997) show. To avoid problems of bias and spurious rejections, this paper applies the endogenous two-break LM unit root test, as derived in Lee and Strazicich (2003).

As from the papers listed above, little attention has been paid on Taiwan to past relative convergence of regional house prices. For the empirical analysis of house prices in Taiwan, some papers empirically test the relationships between house prices and economic variables (Hsueh and Chen 1998; Hsueh 2000; Chen 2001; Lin and Lai 2003; Chen et al. 2007), some investigate house prices and quality (Huang 1999), and others apply the structural time-series model to examine house price series (Chen 2003, 2004). However, these studies have not explored the convergence of regional house prices in Taiwan.

The following presents the purpose and contribution of this paper. Taiwanese data from 1991 to 2006 are first tested, which may be affected greatly by real estate policies, financial crises, and natural disease. This may yield structural changes from the data of regional house prices, which therefore influence the result of the stationary test. Second, this paper applies an alternative, improved testing methodology, such as the endogenous two-break LM unit test as derived in Lee 
and Strazicich (2003), which to our knowledge has not been previously applied in this area, in order to investigate whether the ripple effect exists in Taiwan's regional/ national house price ratios. It is possible that structural breaks have occurred which might affect the result of the convergence of Taiwan's regional house prices. Finally, this paper does find structural breakpoints and looks to match them clearly with the corresponding critical real estate policy, financial crisis, and natural disease. The remainder of the paper is set up as follows. The "Taiwan's Housing Market" section introduces Taiwan's housing market, the "Methodology" section describes the methodology, the "Empirical Findings" section presents the empirical findings, and the "Conclusions" section offers some conclusions.

\section{Taiwan's Housing Market}

Real estate is enormously important in Taiwan due to people's belief in the traditional idea of 'land is wealth'. According to the census of Taiwan's Ministry of Interior in 2006 , the average home ownership rate is over $87 \%$, which is the highest rate in the world. Moreover, the average housing unit vacancy rate in Taiwan is $17.6 \%$, which is far above the average of $3-5 \%$ in other countries. People in Taiwan put all their money into a house and give up other things such as travel, education, leisure, etc.

After reviewing the fluctuations in Taiwan's house market, one sees that before 1986 the change in house prices was not significant compared with that in the following decade. House prices rose sharply during the period 1986-1991, growing by over $300 \%$ in major cities, and stayed at a high level until the mid-1990s, when prices on the island then began a long fall. The events that adversely affected prices included the political tension between mainland China and Taiwan, the Asian financial crisis in 1997, the 2001 global recession that resulted in a demand slowdown for electronics products, and SARS in 2003. After plunging and bottoming out in 2003, Taiwan's house prices have started to climb higher these past few years.

Geographical and regional economic conditions differ much in Taiwan, which are reflected in the value of house prices. The main cities are Taipei City in the northern region, Taichung City in the central region, and Kaohsiung City in the southern region, and these cities are not homogeneous. Although Taichung City and Kaohsiung City took advantage of fast industrialization starting in the 1960s, the economic base changed significantly after 1980s. Over the 1990s, Taiwan's traditional manufacturing industries, which were centered around Taichung City and Kaohsiung City, started to lose their competitiveness. In these two cities more industrial firms moved part of their business overseas, mostly to China's coastal cities, and rearranged their transnational production networks.

The core competitive advantage of Taipei City did not result from traditional industries, but from its strategic node position in transnational flows. Taipei City upgraded itself into the node of a high-technology knowledge center. Taipei City also became the headquarters for the extension of production chains concentrating in the major coastal cities in mainland China. This led Taipei City to develop itself as a nodal city in cross-border connections (Hsu 2005). Taipei City may have gained the 
status of a regional global city (Wang 2003), which has caused housing prices to be much higher in Taipei City.

Table 1 presents the average house price and the ratio of house price to income in these three cities. Comparing these three cities in the third quarter of 2007, Taipei City's average house price is NT\$9,500,000 and is much higher than other citiesindeed at least $50 \%$ higher. For the ratio of house price to income, Taipei City's ratio is 9.9 or at least $35 \%$ higher than elsewhere. Its strong economic strength as a regional global city has helped cause higher prices there. The comparatively low price rises in other regions, especially in southern Taiwan, can be attributed to lose their competitiveness of traditional industrial development in those areas.

Taiwan's housing vacancy rate has been at a high level for at least three decades. According to the latest Taiwan census taken in 2000, the reported average vacancy rate was $17.6 \%$ (Table 2). In fact, the number of households is larger than the total number of housing units (Chen 2000). Comparing the vacancy rate in the three cities for 2000, the rate in Taipei City where land costs are much higher and market demand exceeds supply was $12.2 \%$, yet it was also the lowest rate among the major cities. However, house price fluctuations in Taipei City are significantly different from other regions, because Taipei City is a unique regional global city in Taiwan.

\section{Methodology}

Without allowing for structural breaks, ADF type tests may lead to a wrong decision when the null hypothesis is not rejected. To improve the default of ADF type tests not allowing for possible breaks in the series, Perron (1989) applies a dummy variable at a possible break point in the series for an exogenous level shift in the trend. However, some papers, most notably Christiano (1992), have criticized Perron's known assumption of the break date as 'data mining'. To offer a remedy, Dickey-Fuller type endogenous break tests, such as in Zivot and Andrews (1992) and Perron (1997), among others, propose determining the break point "endogenously" from the data.

When actually more than one break exists, several papers demonstrate that only taking into account one endogenous break is insufficient and causes a loss of information (Lumsdaine and Papell 1997). Following Zivot and Andrews (1992), Lumsdaine and Papell (1997) extend the model with two structural breaks under the alternative hypothesis of the unit root test and additionally allow for breaks in level

Table 1 Average house price and the ratio of house price to income

\begin{tabular}{llc}
\hline Area & Average house price & Ratio of house price to income \\
\hline Taipei City & NT\$9,500,000 & 9.9 \\
Taichung City & NT\$5,500,000 & 6.4 \\
Kaohsiung City & NT\$4,000,000 & 5.2 \\
Taiwan Area & NT $\$ 6,200,000$ & 7.2 \\
\hline
\end{tabular}

Source: Housing Demand Survey for Third Quarter 2007, the Council for Economic Planning and Development 
Table 2 Vacant housing in 2000 and 1990

\begin{tabular}{|c|c|c|c|c|}
\hline \multirow[t]{2}{*}{ Area } & \multicolumn{2}{|l|}{ End of 1990} & \multicolumn{2}{|l|}{ End of 2000} \\
\hline & Vacant housing units & Vacant rate $(\%)$ & Vacant housing units & Vacant rate $(\%)$ \\
\hline Taipei City & 71,007 & 9.40 & 101,102 & 12.20 \\
\hline Taichung City & 41,385 & 19.70 & 101,916 & 26.00 \\
\hline Kaohsiung City & 41,385 & 16.20 & 82,275 & 16.50 \\
\hline Taiwan Area & 674,317 & 13.30 & $1,228,798$ & 17.600 \\
\hline
\end{tabular}

Source: Directorate-General of Budget, Accounting and Statistics

and trend. A common problem of the ADF type tests with endogenous break is their critical values which are derived by assuming no breaks under the null. Nunes et al. (1997) and Lee and Strazicich (2001) find that this assumption causes size distortions in the presence of a unit root with break.

Size properties of Lee and Strazicich's (2003) test are unaffected by breaks under the null, which is contrary to ADF type endogenous break tests, such as in Zivot and Andrews (1992) and others. However, as Lee and Strazicich (2003) indicate, it has higher power, with two structural breaks, and is unaffected by spurious rejections of the null when the series has a unit root with breaks. Hence, results applying this minimum LM test have a significant advantage, whereby the rejection of the null unambiguously shows convergence.

The model of the two-break minimum LM unit root (Lee and Strazicich 2003) can be expressed as follows. According to the LM principle, a unit root test statistic is obtained from the following equation:

$$
\Delta x_{t}=b^{\prime} \Delta Z_{t}+\phi \widetilde{S}_{t-1}+\sum \omega_{i} \Delta \widetilde{S}_{t-i}+\varepsilon_{t}
$$

where $\widetilde{S}_{t}=x_{t}-\widetilde{\psi}_{x}-Z_{t} \widetilde{\delta}, t=2, \ldots, T$. Moreover, $\widetilde{\delta}$ is a vector of coefficients in the regression of $\Delta x_{t}$ on $\Delta Z_{t} ; \widetilde{\psi}_{x}=x_{1}-Z_{1} \widetilde{\delta}$, where $x_{1}$ and $Z_{1}$ are the first observations of $x_{t}$ and $Z_{t}$, respectively; and $\Delta$ is the difference operator. The error term $\varepsilon_{t}$ is assumed to be independently and identically distributed with zero mean and finite variance. Furthermore, $\Delta \widetilde{S}_{t-i}, i=1, \ldots, k$, terms are inserted for correcting serial correlation, and $Z_{t}$ is a vector of exogenous variables. Being equivalent to the twobreak of Perron (1989)'s, Model C with two shifts in level and trend, $Z_{t}=\left[1, t, D_{1 t}, D_{2 t}, D T_{1 t}^{*}, D T_{2 t}^{*}\right]$, where $D_{j t}=1$ for $t \geq T_{B j}+1, j=1,2$, and zero otherwise, $D T_{j t}^{*}=t$ for $t \geq T_{G j}+1, j=1,2$, and zero otherwise; $T_{G j}$ is the time period of the breaks.

The test regression (1) involves $\Delta Z_{t}$ instead of $Z_{t}$, and therefore $\Delta Z_{t}$ becomes $\left[1, G_{1 t}, G_{2 t}, D_{1 t}, D_{2 t}\right]^{\prime}$, where $G_{j t}=\Delta D_{j t}$ and $D_{j t}=\Delta D T_{j t}^{*}, j=1,2$. Under the unit root null hypothesis presented in Equation (1) by $\phi=0$, the test statistics are defined as follows:

$$
\widetilde{\rho}=T \cdot \widetilde{\phi}
$$

where $\widetilde{\tau}=t$-statistic for the null hypothesis $\phi=0$. 
To endogenously determine the location of two breaks $\left(\lambda_{j}=T_{B j} / T, j=1,2\right.$.), the LM test applies a grid search as follows:

$$
\begin{aligned}
& L M_{\rho}=\operatorname{Inf}_{\lambda} \widetilde{\rho}(\lambda) \\
& L M_{\tau}=\operatorname{Inf}_{\lambda} \widetilde{\tau}(\lambda) .
\end{aligned}
$$

To carry out the test, the number of augmentation terms $\Delta \widetilde{S}_{t-i}, i=1, \ldots, k$, which correct for serial correlation in Eq. (1), should first be determined. At each combination of breakpoints $\lambda=\left(\lambda_{1}, \lambda_{2}\right)^{\prime}$ in the time interval [0.1T, 0.9T], where $T$ is the sample size, $k$ is chosen by following a "general to specific" procedure (see Strazicich et al. 2004).

\section{Empirical Findings}

This empirical analysis applies the regional/national house price ratios for the three cities of Taiwan- Taipei City, Taichung City, and Kaohsiung City-from the third quarter of 1991 to the fourth quarter of 2006. The regional/national house price ratios are calculated by subtracting the natural logarithm of the aggregate figure of Taiwan's house prices from the natural logarithm of the house prices for a given region. The data are obtained from the housing index database of Sinyi Real Estate Development Company.

Sinyi's house price index is a constant quality index, using the hedonic housing price model and the pooling data structure, which controls for changes in the quality and location of houses sold. The hedonic model is frequently applied to quantify the effect of different housing and neighborhood characteristics on house prices (Goodman and Thibodeau 1995), but quality characteristics are numerous and difficult to measure, and sometimes the data are unavailable. Additionally, other statistical problems such as multicollinearity and instability of housing characteristic coefficients over time may compromise the usefulness of the hedonic method. Although these debates of the hedonic model exist, the hedonic model is still the widely-followed method to construct house price indices

In order to provide comparative analyses, single region conventional unit root tests are implemented, including ADF and PP (Phillips and Perron 1988) tests, to examine stationarity of the regional/national house price ratios for each city. Table 3

Table 3 ADF and PP unit root tests

\begin{tabular}{llclrr}
\hline \multirow{2}{*}{ City } & \multicolumn{2}{l}{ ADF } & & P-P & \\
\cline { 2 - 3 } \cline { 5 - 6 } & Level & First difference & & Level & First Difference \\
\hline Taipei City & $-1.93(1)$ & $-10.20^{\mathrm{a}}(0)$ & & $-2.14[2.63]$ & $-10.07^{\mathrm{a}}[0.75]$ \\
Taichung City & $-0.93(2)$ & $-8.18^{\mathrm{a}}(1)$ & & $-0.81[3.12]$ & $-10.54^{\mathrm{a}}[1.51]$ \\
Kaohsiung City & $0.33(1)$ & $-11.9^{\mathrm{a}}(0)$ & & $0.21[3.98]$ & $-11.90^{\mathrm{a}}[0.96]$ \\
\hline
\end{tabular}

The form of the equation is a random walk model with drift.(2) The number in () indicates the lag order selected based on the AIC for ADF test, and the number in [] indicates the bandwidth selected on a kernel based for the PP test as suggested by Andrews (1991)

${ }^{a}$ Indicates significance at the 0.05 level 
shows the results of the ADF and PP unit root tests at the 5\% level of significance. The results obviously point out that the ADF and PP tests accept the null of nonstationary regional/national house price ratios for all cities. Consequently, these empirical results of conventional unit root tests not allowing structural breaks fail to support the ripple effect in each city. In other words, shocks to the house prices of each city do not "ripple out" across the nation.

The ADF and PP unit roots tests, not allowing the structural breaks, may be suspect for causing a wrong inference. Avoiding bias and spurious rejections, Lee and Strazicich's (2003) test is used to re-examine the ripple effect of regional house prices in Taiwan. Following the procedure of Niesweadomy and Strazicich (2004), the minimum two-break LM unit root test is applied for the ripple effects of house price ratios. The first step makes sure of two breaks in level and trend for each city and then each break point is examined at the significant 5\% level in an asymptotic normal distribution. If less than two breaks are significant, then the one-break LM unit-root test is performed. If it is not significant, then the no-break LM unit-root test is applied. Table 4 presents the results from Lee and Strazicich (2003)'s test.

At the 5\% level of significance, the regional/national house price ratio of Taipei City fails to reject the unit root null, but the ratios of the other cities reject the unit root null (Table 4). In other words, the results of Lee and Strazicich (2003)'s test are different from the results of the ADF and PP unit roots tests, which are presented to support the ripple effects in two cities: Taichung City and Koushiung City. Therefore, these empirical results of Lee and Strazicich (2003)'s test indicate that ripple effects exist for each city in Taiwan except for Taipei City. It is worth noting that the conventional unit tests which do not consider structural breaks could cause a wrong inference for ripple effects of regional house prices in Taichung City and Kaohsiung City.

The house price shocks stemming from any region in Taiwan, except Taipei City, eventually "ripple out" to have the same effect on all regional house prices. Why does the ripple effect of Taipei City, being different from other cities, not exist? Taipei City's economic strength results in much higher house prices than the other cities. Consequently, shocks to its regional house prices cannot "ripple out" across

Table 4 Two-break minimum LM unit root test

\begin{tabular}{llll}
\hline Area & Test statistic & Critical value breakpoints & Breakpoints \\
\hline Taipei City & $-5.22[4]$ & $0.2,0.8$ & $1994 Q 2\left(-3.19^{\mathrm{a}}\right), 2000 \mathrm{Q} 4\left(3.18^{\mathrm{a}}\right)$ \\
Taichung City & $-6.28^{\mathrm{a}}[3]$ & $0.2,0.6$ & $1998 \mathrm{Q} 4\left(2.18^{\mathrm{a}}\right), 2003 \mathrm{Q} 1\left(2.95^{\mathrm{a}}\right)$ \\
Kaohsiung City & $-5.85^{\mathrm{a}}[5]$ & $0.2,0.8$ & $1997 \mathrm{Q} 2\left(2.26^{\mathrm{a}}\right), 2004 \mathrm{Q} 2\left(-4.58^{\mathrm{a}}\right)$ \\
\hline
\end{tabular}

The number in [] indicates the optimal number of lagged first-differenced terms included in the unit root test to correct for serial correlation

Critical values are shown below for the two-break minimum LM unit root test with a linear trend (Model C) at the $1 \%, 5 \%$, and $10 \%$ levels for a sample of size $T=100$, which are as Table 2 in Lee and Strazicich (2003)

Breakpoints Critical values

$\left(T_{\mathrm{B} 1} / T, T_{\mathrm{Bl}} / T\right) \quad 1 \% \quad 5 \% \quad 10 \%$

$\lambda=(0.2,0.6) \quad-6.41-5.74-5.32$

$\lambda=(0.2,0.8) \quad-6.33-5.71-5.33$

${ }^{a}$ Denotes significance at the $5 \%$ levels, and the value in () is $t$-statistic 
the nation, because the comparatively low price rises in other cities are attributed to losing their competitiveness in traditional industries.

During the 1990s, the traditional manufacturing industries in Taiwan, which were centered around Taichung and Kaohsiung Cites, started to lose their competitiveness. In these two cities more industrial firms moved part of their business overseas. Conversely, the core competitive advantage of Taipei City is not from traditional industries, but from its strategic nodal position in transnational flows and for its headquartering role in the extension of production chains across the Taiwan Strait. Taipei City may have also gained the status of a regional global city (Wang 2003).

Clapp et al. (1995) indicate three sets of factors influencing housing prices: (1) purely local determinants; (2) causes that affect neighboring towns, but not the entire area; (3) factors that exert their influence on the entire area. Taipei City is a regional global city which has resulted in higher house prices, and it is the second factor which affected the house prices of the neighboring area, but not the entire area. Dolde and Tirtiroglu (1997) also demonstrate that changes in new urban economics factors have little consequence for more distant towns.

Table 4 presents the tests of two structural breaks in level and trend in columns 4, revealing that two structural breaks are at the 5\% level of significance in all cities. Related to the first structural break in regional/national house price ratios, the first breakpoint is in 1994Q2 for Taipei City and around 1997-1998 for the other cities. For the structural breakpoint in 1994Q2 for Taipei City, the anticipation of a maximum floor area ratio restriction by the government in 1994 brought about a housing oversupply and then caused the structural breakpoint. What brought about the structural break around 1997-1998 for the other cities? The 1997 Asian financial crisis arising from Thailand started to threaten Taiwan's economy by late 1997. The crisis prompted a decline in economic activities including house prices, although Taiwan saw a lower downturn and had moderate economic growth versus other countries.

With regard to the second structural break in regional/national house price ratios, the breakpoints for Taipei City are 2000Q4, but occur near 2003-2004 for Taichung City and Kaohsiung City. Why did the breakpoints arise? The 1997 Asian financial crisis at first had little effect on Taiwan, but some influences still were exerted in the financial sector from 1998, such as high non-performing loans and the restructuring of community financial institutions, among others. The rigid environment of the financial system lasted until 2000. The breakpoints around 2003-2004 were caused by the SARS epidemic of 2003, which shocked Taiwan's house market. House prices in Taiwan decreased and hit their bottom due to this disease.

\section{Conclusions}

Stationarity results from the assumption under the ripple effect of a steady regional overflow of changes in house prices across an economy. It is worth re-examining the relative studies of a unit root in the ripple effect with structural breaks, if the empirical periods cover unstable social and economic periods. By applying the endogenous two-break LM unit root test derived in Lee and Strazicich (2003), this paper takes a further look at the ripple effects of regional house prices in Taiwan. 
Being different from the empirical results of the conventional unit root tests without structural breaks, the empirical results of the endogenous two-break LM unit root test, as derived in Lee and Strazicich (2003), support the existence of ripple effects for each city in Taiwan except Taipei City. Shocks to regional house prices of Taipei City cannot "ripple out" across the nation, because Taipei City is a regional global city and takes advantage from its strategic nodal position in transnational flows and for its headquartering role in the extension of production chains across the Taiwan Strait. These factors have caused higher house prices there, but did not affect the house prices of the entire area.

The empirical results also illustrate that the development of Taiwan's housing market had two structural breaks in all cities. The first breakpoint occurs in 1994Q2 for Taipei City and 1997-1998 for the other cities. The second structural breaks occur 2000 for Taipei City and 2003-2004 for Taichung City and Kaohsiung City. These structural breaks in the housing market were caused by real estate policies, financial crises, and natural disease. The anticipation of a maximum floor area ratio restriction by the government in 1994 brought about corresponding structural breaks. The Asian financial crisis in 1997 gave rise to breakpoints near 1997 and 1998. The structural breaks in 2000 resulted from the tightening environment of Taiwan's financial sector from 1998. The SARS epidemic in 2003 brought about breakpoints in 2003 and 2004.

As for the final observation worth noting, these empirical results are inferred using Sinyi's house price index, with quality constant indices based on the hedonic model. The debates of using a hedonic method include numerous quality characteristics, more difficult to measure quality characteristics, the data of characteristics are unavailable, and other statistical problems. If these debates compromise the usefulness of this house price index, the empirical results of this paper may have to be amended.

Acknowledgements The author thanks Prof. James B. Kau, the editor, and an anonymous referee for their valuable suggestions and comments. I also thanks Prof. Shu-Jung, Chang Lee for her helps in empirical procedures. Errors and omissions, if any, are my own.

\section{References}

Alexander, C., \& Barrow, M. (1994). Seasonality and cointegration of regional house prices in the UK. Urban Studies, 31, 1667-1689. doi:10.1080/00420989420081571.

Andrews, D. (1991). Heteroskedasticity and autocorrelation consistent covariance matrix estimation. Econometrica, 59, 817-858. doi:10.2307/2938229.

Ashworth, J., \& Parker, S. (1997). Modelling regional house prices in the UK. Scottish Journal of Political Economy, 44, 225-246. doi:10.1111/1467-9485.00055.

Berg, L. (2002). Prices on the second-hand market for Swedish family houses: correlation, causation and determinants. European Journal of House Policy, 2(1), 1-24. doi:10.1080/14616710110120568.

Chen, Y. J. (2000). Modeling the impacts of vacancy taxes on the Taiwan housing market. Proceedings of the National Science Council, Republic of China, 11(2), 148-155.

Chen, N. K. (2001). Asset price fluctuations in Taiwan: Evidence from stock and real estate prices 1973 to 1992. Journal of Asian Economics, 12, 215-232. doi:10.1016/S1049-0078(01)00083-5.

Chen, M. C. (2003). Time-series properties and modelling of house prices in Taipei area: An application of the structural time-series model. Journal of Housing Studies, 12(2), 69-90.

Chen, M. C. (2004). An analysis of the trends and cyclical behaviours of house prices in the Asian markets. Journal of Property Investment and Finance, 22(1), 55-75. doi:10.1108/14635780410525144. 
Chen, M. L., Tsai, I. C., \& Chang, C. O. (2007). House prices and household income: Do they move apart? Evidence from Taiwan. Habitat International, 31(2), 243-256. doi:10.1016/j.habita tint.2007.02.005.

Christiano, L. J. (1992). Searching for break in GNP. Journal of Business \& Economic Statistics, 10, 237250. doi:10.2307/1391540.

Clapp, J. M., Dolde, W., \& Tirtiroglu, D. (1995). Imperfect information and investor inferences from housing price dynamics. Real Estate Economics, 23, 239-269. doi:10.1111/1540-6229.00665.

Cook, S. (2003). The convergence of regional house prices in the UK. Urban Studies, 40(11), 2285-2294. doi:10.1080/0042098032000123295.

Cook, S. (2005). Regional house price behaviour in the UK: application of a joint testing procedure. Physica A, 345, 611-621.

Dickey, D., \& Fuller, W. (1979). Distribution of the estimators for autoregressive time series with a unit root. Journal of the American Statistical Association, 74, 427-431. doi:10.2307/2286348.

Dolde, W., \& Tirtiroglu, D. (1997). Temporal and spatial information diffusion in real estate price changes and variances. Real Estate Economics, 25, 539-565. doi:10.1111/1540-6229.00727.

Elliott, G., Rothenberg, T. J., \& Stock, J. H. (1996). Efficient tests for an autoregressive unit root. Economic Record, 77, 252-269.

Engle, R. F., \& Granger, C. W. J. (1987). Cointegration and error correction: representation, estimation and testing. Econometrica, 55, 251-276. doi:10.2307/1913236.

Engle, R. F., \& Smith, A. D. (1999). Stochastic permanent breaks. Review of Economics and Statistics, 81, 553-574. doi:10.1162/003465399558382.

Goodman, A., \& Thibodeau, T. (1995). Aged-related heteroskedasticity in hedonic house price equations. Journal of Housing Research, 6, 25-42.

Ho, L. S., Ma, Y., \& Haurin, D. R. (2007). Domino effects within a housing market: the transmission of house price changes across quality tiers. Journal of Real Estate Finance and Economics. www. springerlink.com/content/>.

Holmes, M. J., \& Grimes, A. (2005). Is there long-run convergence of regional house prices in the UK? Motu Working Paper 05-11, Motu Economic and Public Policy Research.

Hsu, J. (2005). A site of transnationalism in the "Ungrounded Empire": Taipei as an interface city in the cross-border business networks. Geoforum, 36(5), 654-666. doi:10.1016/j.geoforum.2004.11.004.

Hsueh, L. M. (2000). The relationship between housing price, tenure choice and saving behavior in Taiwan. International Real Estate Review, 3(1), 11-33.

Hsueh, L. M., \& Chen, H. L. (1998). A comparison of household expenditure by tenure choice-Taiwan evidence. Journal of Housing Studies, 7, 21-40.

Huang, C. H. (1999). The housing price and quality of Taiwan. The Proceedings of 1999 Annual Conference of the Chinese Society of Housing Study, 391-400.

Johansen, S. (1988). Statistical analysis of cointegration vectors. Journal of Economic Dynamics and Control, 12, 231-254. doi:10.1016/0165-1889(88)90041-3.

Kwiatkowoski, D., Phillips, P., Chmidt, P., \& Shin, J. (1992). Testing the null hypothesis of stationarity against the alternative of a unit root. Journal of Econometrics, 54(1-3), 159-178. doi:10.1016/03044076(92)90104-Y.

Lee, J., \& Strazicich, M. C. (2001). Break point estimation and spurious rejections with endogenous unit root tests. Oxford Bulletin of Economics and Statistics, 63, 535-558. doi:10.1111/1468-0084.00234.

Lee, J., \& Strazicich, M. C. (2003). Minimum LM unit root test with two structural breaks. Review of Economics and Statistics, 85, 1082-1089. doi:10.1162/003465303772815961.

Lin, C. C., \& Lai, Y. F. (2003). Housing Prices, mortgage payments, and savings behavior in Taiwan: A time series analysis. Asian Economic Journal, 17(4), 407-425. doi:10.1111/j.1467-8381.2003.00193.x.

Lumsdaine, R., \& Papell, D. (1997). Multiple trend breaks and the unit-root hypothesis. Review of Economics and Statistics, 79(2), 212-218. doi:10.1162/003465397556791.

MacDonald, R., \& Taylor, M. (1993). Regional house prices in Britain: long-run relationships and shortrun dynamics. Scottish Journal of Political Economy, 40, 43-55. doi:10.1111/j.1467-9485.1993. tb00636.x.

Meen, G. (1999). Regional house prices and the ripple effect: a new interpretation. Housing Studies, 14, 733-753. doi:10.1080/02673039982524.

Newbold, P., Leybourne, S., \& Wohar, M. (2001). Trend-stationarity, difference-stationarity or neither: further diagnostic tests with an application to U.S. real GNP, 1875-1993. Journal of Economics and Business, 53, 85-102. doi:10.1016/S0148-6195(00)00035-7.

Nieswiadomy, M. L., \& Strazicich, M. C. (2004). Are political freedoms converging? Economic Inquiry, 42(2), 323-340. doi:10.1093/ei/cbh064. 
Ng, S., \& Perron, P. (2001). Lag length selection and the construction of unit root tests with good size and power. Econometrica, 69, 1519-1554. doi:10.1111/1468-0262.00256.

Nunes, L., Newbold, P., \& Kuan, C. (1997). Testing for unit roots with breaks: evidence on the great crash and the unit root hypothesis reconsidered. Oxford Bulletin of Economics and Statistics, 59(4), 435438. doi:10.1111/1468-0084.00076.

Perron, P. (1989). The great crash, the oil price shock and the unit root hypothesis. Econometrica, 57(6), 1361-1401. doi:10.2307/1913712.

Perron, P. (1997). Further evidence on breaking trend functions in macroeconomic variables. Journal of Econometrics, 80, 355-385. doi:10.1016/S0304-4076(97)00049-3.

Phillips, P., \& Perron, P. (1988). Testing for a unit root in time series regressions. Biometrika, 75, 335346. doi:10.1093/biomet/75.2.335.

Pippenger, M., \& Goering, G. (1993). A note on the empirical power of unit root tests under threshold processes. Oxford Bulletin of Economics and Statistics, 55, 473-481.

Sing, T. F., Tsai, I. C., \& Chen, M. C. (2006). Price dynamics in public and private housing markets in Singapore. Journal of Housing Economics, 15, 305-320. doi:10.1016/j.jhe.2006.09.006.

Strazicich, M. C., Lee, J., \& Day, E. (2004). Are incomes converging among OECD countries? Time series evidence with two structural breaks. Journal of Macroeconomics, 26, 131-145. doi:10.1016/j. jmacro.2002.11.001.

Wang, C. (2003). Taipei as a Global City: A theoretical and empirical examination. Urban Studies, 40, 309-333. doi:10.1080/00420980220080291.

Zivot, E., \& Andrews, W. D. (1992). Further evidence on the great crash, the oil-price shock, and the unitroot hypothesis. Journal of Business \& Economic Statistics, 10, 251-270. doi:10.2307/1391541. 